\title{
COMO GARANTIR MEDIAÇÃO, INTERAÇÃO, E QUALIDADE NO PROCESSO DE ENSINO APRENDIZAGEM POR MEIO DA TUTOTIA ON LINE
}

UBERABA/MG MAIO/2018

\author{
CAMILLA DE OLIVEIRA VIEIRA - uni - gestor.administracao@uniube.br \\ SILVIA DENISE DOS SANTOS BISINOTTO - UNIUBE - silvia.bizinoto@uniube.br \\ ROBERTO LINS MARQUES - Uniube - roberto.marques@uniube.br
}

\author{
Tipo: Relato de Experiência Inovadora (EI) \\ Categoria: Conteúdos e Habilidades \\ Setor Educacional: EDUCAÇÃO SUPERIOR
}

\begin{abstract}
RESUMO
É comum encontramos opiniões, das mais variadas formas, sobre os impactos da tecnologia para $o$ campo da educação. A intensidade das mudanças que os novos tempos proporcionam é referida ora com mais suavidade, ora com tons apocalípticos, não sendo raro encontrarmos textos que sugerem a completa substituição do professor, da sala de aula e, até, dos próprios alunos. Tecnologias novas são sempre aguardadas com muita ansiedade, porém não percebemos igual obstinação pelo estudo das tecnologias já disponíveis e que nos parecem suficientes para de imediato propiciar uma singular modificação nos ambientes educacionais. Percebemos com frequência a insatisfação de muitos alunos diante das metodologias tradicionais sobretudo aquelas que se mantém pautadas em aulas meramente expositivas. Diante disso, a pergunta que se faz de imediato é: se boas tecnologias já existem, se elas se encontram facilmente à disposição da maior parte dos professores e alunos, se os recursos são de simples manejo, qual a razão desse sentimento de descompasso entre docentes, discentes e 0 ambiente de ensino? Para problematizar ainda mais esta questão socializamos por meio deste artigo a experiência da EAD Uniube em utilizar tecnologias da Educação a Distância para garantir interação, mediação e qualidade no processo de ensino aprendizagem. Segue um relato da experiência percebida na Disciplina Instituições do Direito por meio da tutoria on line.
\end{abstract}

Palavras-chave: Educação a distância. Tutoria. Humanização 
Garantir interação, mediação e qualidade compreendem um dos maiores desafios das instituições de ensino superior que oferecem Educação a Distância. Frente a essas preocupações a Uniube tem buscado fortalecer a formação do corpo docente com vistas a consolidar um modelo coerente e competitivo. É importante, portanto, que o professor conheça o projeto pedagógico e os objetivos do curso, buscando a integração e a consolidação dos conhecimentos; que ele se comprometa com a Instituição e com os programas institucionais; que atue em concordância com as decisões colegiadas; esteja atento a fatores internos e externos que contribuam para mudanças nas estratégias, metodologias e conteúdo dos componentes; atue com ética e postura crítica, empreendedora e proativa demonstrando compromisso com os valores humanos em sua atuação. É necessário que o professor invista continuamente em sua formação acadêmica e profissional e demonstre compromisso com a questão da responsabilidade social.

$\mathrm{Na} E A D$, a tutoria é desenvolvida por professores-tutores que realizam o acompanhamento técnico-científico em cada uma das disciplinas curriculares, por meio do ambiente virtual de aprendizagem. Do mesmo modo que Justino el al. (2010), consideramos que o professor-tutor é fundamental na contribuição da aprendizagem do aluno, assim como fundamental para comunicar a proposta pedagógica da instituição. Conforme Cortelazzo (2008, p. 310) "A interação social é o ponto de partida para uma parceria sólida e produtiva, essencial à realização de projetos que impliquem construção conjunta tanto na educação presencial quanto na modalidade a distância". Nesta lógica, para que a interação ocorra de maneira primorosa, entendemos que os professorestutores precisam ter graduação na área de formação do curso, especialização mínima em lato sensu e capacitação em EAD, com domínio de conhecimentos relacionados a formação comum e específica e devem ser capacitados para usar as mídias e o Ambiente virtual de aprendizagem AVA, adotados no projeto EAD Uniube.

Uma vez que possui grande responsabilidade pelo processo de ensino-aprendizagem que se desenvolve no Ambiente Virtual de Aprendizagem, AVA Uniube on-line, o professor-tutor media as aprendizagens individuais e coletivas, corrigindo atividades, tirando dúvidas de conteúdo, interagindo e estimulando os alunos para os estudos e as atividades a serem realizadas no AVA, bem como orientando sobre o que deverá ser feito em cada semana de estudos. Algumas das principais funções deste professor-tutor são:

- compreender e fazer uso correto de todas as ferramentas do AVA, inerentes ao processo de ensino-aprendizagem;

- conhecer todo o material que será disponibilizado para cada disciplina sob sua 
responsabilidade;

- acolher bem o(a) aluno(a) na sala virtual da(s) disciplina(s), por meio da ferramenta "Palavra do Tutor", orientando-o e estimulando-o para os estudos e atividades que deve realizar;

- ser mediador da aprendizagem, apontando caminhos, intervindo sempre que necessário, desafiando e provocando o(a) aluno(a) para a construção de novos saberes;

- ser pontual, nas correções das atividades dos alunos, dando respostas rápidas às dúvidas apresentadas por eles, respeitando os prazos e critérios estabelecidos pela instituição;

- desenvolver uma postura interdisciplinar junto ao(à) aluno(a) no decorrer dos estudos buscando fazer com que estabeleçam relações entre os conteúdos;

- ser responsável por estabelecer relações positivas com o(a) aluno(a) ou grupo de alunos, de forma a construir um clima propício e favorável ao desenvolvimento e sucesso do processo de ensino-aprendizagem que se desenvolve no AVA;

Para que estas funções sejam exercidas com maestria, buscamos novos métodos de interação para com os alunos que partem não da implementação de mais tecnologias, mas sim do fortalecimento do "elemento humano" tão necessário para a aprendizagem. Percebemos que a busca de um sistema automatizado de pronto atendimento ao aluno estava suprimindo o elemento humano do professor e, em razão disso, era necessário reconstruir o método para propiciar ao discente o sentimento de que ele não se encontrava sozinho em seus estudos, que a distância que o separa de seus professores não seria uma barreira a uma maior interação entre ambos. Partimos da concepção de que um método humanizado é um campo propício para transmitir ao aluno que a Universidade realmente se importa com o seu desenvolvimento.

Neste sentido, o presente estudo, compreende um relato de nossas principais atividades realizadas nos últimos 2 anos na disciplina Instituições do Direito, pela qual obtivemos um inédito retorno de significativa parte dos discentes que manifestaram ter nutrido um grande gosto pela disciplina oferecida de forma humanizada. Como é natural de toda pesquisa, não pretendemos dar uma solução para as dificuldades da educação, mas temos o inegável intuito de externar que a superação de alguns dos principais entraves no ensino à distância atual não está somente na busca por tecnologias futuras, mas no resgate do elemento humano que, acreditamos, deva permear o ensino atual, seja qual o método ou o sistema de sua implementação.

\section{O contato com o aluno a distância não pode ser distante}


Em uma sala de aula presencial, a convivência nos permite uma interação ampla, visando conhecer os alunos melhor e seus anseios no que se refere ao aprendizado. $\mathrm{Na}$ Educação a Distância, ao contrário do que possa parecer em uma reflexão apressada, essa interação pode ser ainda superior. Vygotsky e Wallon são importantes representantes da corrente histórico-cultural que trazem contribuições significativas aos estudos das relações entre afetividade e aprendizagem (LONGHI et al, 2009). De acordo com Oliveira (1992),

\footnotetext{
Vygotsky nos apresenta uma abordagem unificadora das dimensões cognitivas e afetivas do funcionamento psicológico do ser humano. Reconhecendo as bases orgânicas sobre as quais as emoções humanas se desenvolvem, buscou no desenvolvimento da linguagem - sistema simbólico básico de todos os grupos humanos os elementos fundamentais para compreender as origens do psiquismo. A afetividade atua na construção das relações do ser humano dentro de uma perspectiva social e cultural. É na linguagem que se constituem e se expressam os modos de vida culturalmente elaborados.
}

As interações normalmente começam com o ato de "olhar o outro". Mas como "olhar o outro" em um sistema virtual? Muitos são os aspectos fenomenológicos que nos permitem. Fazendo uma aplicação da fenomenologia à interação entre docente e discentes no ensino à distância, o primeiro aspecto a ser observado é quais as informações que tínhamos dos discentes quando recebíamos uma pergunta ou, caso outro, desejávamos nos comunicar com ele. Tais informações se resumiam a um número de Registro Acadêmico - RA, um nome, uma imagem (foto disponibilizada pelo próprio discente) e seu local de origem (cidade e Estado-membro). Outras informações seriam desejáveis? Com certeza que sim, mas era o que tínhamos e com os quais deveríamos trabalhar. E não podemos negar que se trata de um bom começo. Logo notamos que parte considerável dos discentes não inseria suas fotos nos campos predeterminados, e que a inserção da imagem não era incentivada. Como precisávamos "olhar o outro", a fotografia era um elemento precioso e passamos a convidar os discentes a inseri-las. Como o ensino é um caminho duplo, também inserimos nossas próprias imagens, para que eles também nos vissem. E a justificativa do pedido que lhes fizemos foi o desejo de conhecê-los mais e melhor.

Pudemos constatar que tal comportamento, o simples gesto de pedir a inserção de uma foto para conhecê-los, por mais singelo que o seja, despertou a atenção dos discentes, fazendo-os se sentirem valorizados. Aquele professor-tutor, que tão mecanizado lhes parecia, passou a desejar conhecê-los. Isso, e tão somente isso, fez uma diferença fundamental em nossos trabalhos. Recebemos vários comunicados de alunos informando que tinham inserido suas fotografias e interpretamos essas mensagens como o desejo de serem vistos. Um simples pedido de inserção de fotografia, básico em qualquer tecnologia, já resultou em consideráveis resultados nesse intuito de valorização da interação. 
A ciência quanto ao local de origem de nossos discentes também se mostrou uma informação valiosa. Muitas vezes já conhecíamos informações sobre as cidades deles, algumas até conhecíamos de momentos outros, e a elaboração de comentários e questionamentos sobre seus municípios de origem também se revelaram um ótimo caminho para a interação desejada e humanização do tratamento. Sentimos que a maioria dos discentes teve orgulho ao comentar de suas origens e isso se mostrou extremamente compensador para todos os envolvidos. Talvez o maior sucesso obtido nesses primeiros contatos foi demonstrar que sim, seus professores e a própria Universidade, se importam com ele. E o vínculo de cumplicidade entre aluno e docente, que nos parece essencial no desenvolvimento discente, estava constituído.

\section{Os contatos pelas ferramentas "Tira-Dúvidas" e "Palavra do Tutor"}

A interação docente-discente deve ser muito mais ampla que meros contatos esporádicos, limitados às dúvidas que por ventura surgirem. Inicialmente utilizávamos outro canal de comunicação, chamado de "Central de Mensagens", que sempre funcionou como um e-mail entre professor e aluno. $O$ entrave que nos pareceu é que, em épocas de conversas fluídas via Messenger e WhatsApp, o envio e recebimento de emails tem se tornado uma comunicação quase que formal, o que não atendia aos nossos desejos. Era preciso inovar uma vez que a qualidade da interação na EAD é o que minimiza os efeitos da distância física, existente entre tutor e aluno (PIMENTEL, 2010). Tentando incrementar essa comunicação, a Universidade desenvolveu uma segunda ferramenta de comunicação, nominada de "Palavra do Tutor", por meio da qual o docente pode dirigir uma comunicação a todos os discentes de uma determinada matéria e período, à semelhança de uma circular. O que diferencia tal ferramenta é a possibilidade de $\mathrm{o}$ aluno avaliar o comunicado, concedendo notas às mensagens recebidas, que vão de 01 (ruim) a 05 (ótima), bem como escrever um feedback.

Como adequar as ferramentas disponíveis à necessidade de maior interação entre docente e discentes? Levando em consideração que os sentimentos de estima são frutos da convivência, a melhor alternativa que visualizamos foi o uso maciço de tais ferramentas, sobretudo da "Palavra do Tutor". E assim começamos.Todas as semanas, ao menos duas ou três mensagens são direcionadas aos alunos permitindo-nos envolver assuntos que vão além dos temas estudados. Para criar um vínculo de amizade, um dos exemplos que obtivemos sucesso foi a utilização do futebol como uma porta para a aproximação. Nos recados dados às segundas-feiras, por exemplo, ao lado de algum lembrete ou esclarecimento sobre a matéria estudada, não faltam comentários sobre os jogos de futebol do fim de semana. Como é fato notório, a maioria dos brasileiros (e de nossos discentes) tem um time ao qual dedicam especial afeto. E os 
comentários sobre futebol, inseridos nas relevantes mensagens envolvendo a matéria, tiveram a força de instigar os discentes a replicar nossos comentários, fazendo com que não só despertassem maior atenção quanto às mensagens disponibilizadas, mas também representando um convite para que saíssem da costumeira passividade. Assim, conseguimos alcançar um triplo objetivo: a) interagir com maior eficiência e retorno; b) dar melhor conhecimento sobre os assuntos mais relevantes da disciplina, e c) solidificar, continuamente, a interação humanizada.

\section{Complementação das leituras com materiais sempre diversificados}

Outro aspecto utilizado e que resultou em grande aceitação pelos discentes foi a complementação das leituras com músicas, pequenos filmes e até videoaulas curtas e gravadas de maneira informal, com o uso de um celular. Os cursos à distância da Universidade de Uberaba possuem videoaulas como material didático, normalmente de média ou longa duração, visando expor o tema em estudo. São aulas gravadas no modelo expositivo padrão, em estúdios, com formato próprio e de bastante formalidade. Em complementação, passamos a realizar gravações de vídeos curtos preferencialmente sem cortes, dando um ar de informalidade ao conteúdo. Em determinadas situações, explicávamos a matéria enquanto fazíamos uma caminhada; em outras, indicávamos trechos de músicas ou de filmes renomados; e, em situações excepcionais, sobretudo quando desejávamos fazer um alerta quanto aos prazos que estavam se findando, fazíamos gravações como uso de alguma fantasia de personagens sombrios. O número de visualizações dos vídeos nos permitiu concluir que cerca de $83 \%$ de nossos alunos assistiram aos vídeos integralmente. De nada nos adiantaria se os alunos fossem motivados por mera curiosidade e abandonassem os vídeos após passados 1 ou 2 minutos.

Nossa meta também foi a gravação de vídeos curtos se comparados com as videoaulas institucionais, de modo que não deveriam ultrapassar 10 minutos. Os retornos obtidos dos discentes nos permitiram concluir que 10 vídeos de 06 minutos têm muito mais aceitação que um único vídeo de 60 minutos. Estamos na época das informações ágeis, de forma que temos o objetivo de não mais utilizar vídeos de longa duração, exceto os institucionais. Essa preocupação em disponibilizar vídeos formais e informais, bem como indicar músicas e filmes, vem da compreensão obtida de que existem diferentes anseios entre nossos alunos, havendo aqueles que se adaptam melhor ao ensino mais tradicional, bem como aqueles que preferem um ensino mais informalizado. Nosso objetivo é disponibilizar ambos os caminhos, deixando ao mesmo que decida qual atenda melhor aos seus interesses. Por fim, se fizermos uma comparação entre os métodos aqui propostos e aqueles praticados em salas-de-aula presenciais, já podemos 
perceber que a variedade metodológica se faz muito mais rica no ensino à distância, que oportuniza possibilidades que são distantes em um ambiente presencial.

\section{Outras práticas implantadas visando à humanização e interação}

A par de toda a sensibilidade no primeiro contato e criação de métodos alternativos de aprendizagem, outros norteamentos foram dados à disciplina "Instituições do Direito", que nos pareceram fundamentais para incentivar a interação humanizada entre docentes e discentes.

Envolvimento maior na resposta das perguntas formuladas pelos discentes: adotamos como princípio nunca responder uma pergunta de forma direta, ou seja, somente com a solução da dúvida. Quando o aluno faz um questionamento, é uma oportunidade para se abrir um amplo diálogo com ele. Hack (2010) alude sobre a importância do tutor estabelecer uma comunicação dialógica. Ou seja:

\footnotetext{
uma constante interlocução entre sujeitos que vai além do cumprimento de provas e tarefas, prescindindo um cuidado no caminhar da aprendizagem em que a troca de informação e conhecimento é crescente. Pois; Ao romper com a prevalência da transmissão monóloga, tão comum em algumas salas de aula, o tutor se converte em formulador de problemas, provocador de interrogações, coordenador de equipes de trabalho e sistematizador de experiências (HACK, 2010, p. 121).
}

Começamos sempre por agradecer a pergunta, afirmando que isso justifica o nosso trabalho e nos dignifica, pois sabemos que estamos efetivamente contribuindo com 0 outro. Esse "preâmbulo" nos parece fundamental inclusive para transmitir ao aluno a tranquilidade para que faça inúmeras outras perguntas e somente após terem realizado seus estudos. Percebemos que muitos se sentiam constrangidos ao elaborar questões, iniciando suas perguntas com pedidos de desculpas. Tal situação necessitava ser tratada, para transmitir ao discente um novo olhar sobre o seu aprendizado, ou seja, demonstrar-lhe que o professor era seu aliado e seu companheiro efetivo nesse caminhar. Ao responder a qualquer indagação, aproveitamos para perguntar ao discente como estavam indo seus estudos, se podemos ajudar em algum assunto que ficou pendente, comentamos questões da atualidade (notícias dos telejornais ou até indicação de filmes), indicamos a ele novos métodos de estudo, Ihe confidenciamos novidades que estavam por surgir na matéria, perguntamos pelo seu dia-a-dia, seu planejamento para as férias (sugeríamos que tirasse alguns dias para conhecer sua Universidade) etc. Ou seja, tentamos demonstrar que é verdadeiramente uma conversa entre sujeitos com objetivos semelhantes.

Evitamos respostas prontas e padrões a todos os alunos. Se o que pretendemos é 
inserir um elemento humano no tratamento ao discente isso nos parecem um aviltamento das legítimas expectativas do discente. Não acreditamos que um docente, que se coloque no lugar de seu discente, convença-se de que tais respostas prontas realmente seriam as desejadas. Cada aluno é um ser humano diferente, inserido em um ambiente único, que aspira objetivos diversos e enfrenta dificuldades personalíssimas, de forma que o mínimo que espera de seu orientador é que tenha sensibilidade para tais singularidades. Não se pode, obviamente, pedir ao professor que conheça todas as individualidades, mas o mínimo que se espera é que o docente não feche os olhos para a existência delas.

Realização de provas em vídeo: na disciplina "Instituições do Direito", há uma atividade à distância de singular importância, que é a "Avaliação Continuada em formato de Questão Aberta - ACQA", valorada em 21 pontos e que deve ser apresentada até a sexta semana do curso. Nessa questão, há uma grande liberdade ao professor para confeccioná-la da forma que desejar, desde que não seja por questões de múltipla escolha. Anteriormente a disciplina contava com questões discursivas solicitando respostas escritas. Grande foi o nosso desafio inicial ao corrigirmos tais atividades, pois significativa parcela das respostas eram reprodução de trechos de textos retirados da internet. Simplesmente punir o aluno, com nota zero, parecia nos transformar em um ensino punitivo, fugindo completamente dos objetivos traçados pela Instituição.

Em virtude disso, essas ACQA's foram, durante longo tempo, o nosso desafio maior. $\mathrm{E}$ uma solução que nos pareceu viável foi a substituição das respostas escritas por respostas em vídeo. Boa parte dos alunos possuem uma eficiente ferramenta de captação de imagem e vídeo em mãos, que é o celular. Assim, foi solicitado que apresentassem suas respostas em vídeo. Em um primeiro momento, esta proposta causou resistências. Muitos se sentiam extremamente tímidos, uns nunca tinham feito esse tipo de gravação, outros se achavam feios etc. Eram questões a serem trabalhadas com eles, pacientemente, visando superar suas dificuldades e muitos sentimentos de baixa autoestima. O que iniciou-se como uma mera atividade avaliativa tornou-se uma poderosa ferramenta para melhorar nosso material de estudo disponibilizado, incluindo o desenvolvimento de competências que até então não tinham sido pensadas: elementos como a postura, a capacidade de bem se expressar (falar com clareza e firmeza), de bem argumentar (ser convincente), o raciocínio lógico durante a fala (e não somente na escrita), o vestir-se adequadamente etc. Afinal, tal qual o conhecimento científico, são elementos valiosíssimos no cotidiano profissional de todos eles.

Ao prepará-los para o mercado de trabalho entendemos que está incluída em nossa obrigação docente também a possibilidade de orientarmos como se apresentar diante 
das pessoas, de comunicar-se adequadamente para uma entrevista de emprego, de demonstrar-Ihes que não são menores e que possuem aptidão para comunicar-se profissionalmente inclusive por ambientes virtuais etc.

Para a avaliação por vídeo, a dividimos em três momentos (critérios que estão sendo constantemente revisados): 1)A apresentação discente: em um primeiro momento, o aluno é convidado a apresentar a si mesmo e a sua realidade: seu nome, sua origem, sua comunidade, os aspectos positivos e negativos de seu local de origem etc. $\mathrm{O}$ que ele entender por necessário para dizer aos professores quem ele é. Muitos dos vídeos recebidos incluíram imagens das comunidades em que moram, o que foi (e ainda o é) uma fonte de informação riquíssima para a reformulação constante de nossas disciplinas. Esse momento oportuniza que nós, professores, tenhamos um contato como jamais tivemos com nosso aluno, sobretudo para tentar observar, o quanto possível, seus anseios quanto ao ensino. 2) $O$ desenvolvimento do tema: nesse segundo momento, é sugerido um tema de nossa disciplina para que ele discorra oralmente. Esse é um momento de colaboração ímpar, pois aqui podemos perceber (e orientá-los) sobre sua postura, sobre como fazer uma explicação científica passo-a-passo e como falar com clareza e com firmeza. 3)A conclusão: nesse momento, orientamos a fazer uma junção do conhecimento científico até então adquirido e sua realidade, oportunidade em que ele nos responderá qual o aproveitamento da disciplina em sua vida atual ou futura atividade profissional. Nesse aspecto interpretamos que, mais que uma avaliação discente, trata-se de um momento em que o aluno avalia a nossa disciplina, pois uma eventual dificuldade em fazer essa inserção pode representar que a disciplina se encontra desassociada de sua realidade, merecendo revisões. E essa revisão pode se dar em duplo aspecto, ou seja, tanto por estarmos tratando de temas específicos que não Ihe serão úteis, como por não tratarmos de temas dos quais eles tenham anseio

\section{?Resultados obtidos}

Pudemos captar que toda essa modificação de postura no método de ensino e no interesse dos discentes dessa disciplina tem conseguido resultados que consideramos altamente satisfatórios, traduzindo-se num sentimento coletivo de maior envolvimento e satisfação com o curso, pois mitigada a sensação de que estavam desenvolvendo seus estudos de maneira isolada. A par disso, as novas atividades desenvolvidas, sobretudo com a avaliação em vídeo, abriram as portas para uma colaboração muito mais efetiva e pontual dos docentes no caminhar educacional dos discentes, representando ganhos mútuos.

O objetivo de todo esse trabalho, enfim, é lançar o debate no sentido de que as 
tecnologias necessárias para um trabalho muito mais vivo, humanizado e proveitoso já encontram-se presentes, sendo preciso, agora, apenas um pouco mais do envolvimento docente. Entendemos ser imprescindível que 0 professor se comprometa verdadeiramente com o processo, transparecendo essa preocupação para o aluno. Isso o torna mais presente e mais assíduo ao ensino à distância, diminuindo inclusive a evasão. O que se espera - e tão somente o que se espera - é que o aluno seja sempre valorizado como ser humano, independentemente de estar à nossa frente ou do outro lado do país, e necessita de nossa orientação contínua e de fácil acesso, missões essas que nos norteiam em nosso eterno aprendizado-docente. Diante de todo o exposto, compreende-se o tutor como aquele que facilita, avalia, medeia, orienta; o que "caminha com" o aluno na busca pelo conhecimento; Ele é o profissional participativo, que estuda junto com o aluno caminhos que possam transformar a atividade de aprendizagem em um ato significativo, engajando o aluno ativamente no processo de aquisição da informação e da sua transformação em conhecimento (MUNHOZ, 2003, p.13). Tiramos como aprendizado deste formato de realizar tutoria a certeza de que o aluno envolvido de forma ativa e atuante em seu processo de aprendizagem, e o professor comprometido de maneira humanizada, mediando discussões e instigando a busca para a solução de problemas, amplia significativamente a chance do sucesso em todo o percurso de aprendizado e de formação profissional do estudante.

\section{REFERÊNCIAS}

CORTELAZZO, Iolanda Bueno de Camargo. Tutoria e autoria: novas funções provocando novos desafios na educação a distância. Revista EccoS, São Paulo, vol. 10, n. 2, p.307-325, jul-dez, 2008 JUSTINO, Erika Carolline; CUNHA, Jurema Tussi; CUNHA, Marilza Helena Candi. EAD: A Educação do século XXI. Anuário da produção acadêmica docente, vol. 4, n. 8, ago, 2010. HACK, Josias Ricardo. Comunicação dialógica na educação superior a distância: a importância do papel do tutor. Signo e pensamento 56. Eje temático. Vol. XXIX - enero - Jun. 2010. P. 114-123. LONGHI, Magali T.; BEHAR, Patrícia.; BERCHT, M. A busca da dimensão afetiva em ambientes virtuais de aprendizagem. In: BEHAR, Patrícia e colaboradores. Modelos pedagógicos em educação a distância. Porto Alegre: Artmed, 2009. p. 204-229. OLIVEIRA, M. K. O problema da afetividade em Vygotsky. In: DE LA TAILLE, Yves. Piaget, Vygotsky e Wallon: teorias psicogenéticas em discussão. São Paulo: Summus, 1992. MUNHOZ, Antonio Siemsen. A educação a distância em busca do tutor ideal. Revista digital da CVA. Vol. 2, n. 5, set, 2003 PIMENTEL, Fernando Silvio Cavalcanti. Interações no ambiente virtual de aprendizagem. Revista EDAPECI, Alagoas, n. 05, p. 28-44, 2010. 